\title{
Bandwidth and Efficiency Enhancement of Rectangular Patch Antenna for SHF Applications
}

\author{
Mousaab M. Nahas \\ Department of Electrical and Electronic Engineering \\ Faculty of Engineering \\ University of Jeddah \\ Jeddah, Saudi Arabia \\ mnahas1@uj.edu.sa
}

\author{
Mouaaz Nahas \\ Department of Electrical Engineering \\ College of Engineering and Islamic Architecture \\ Umm Al-Qura University \\ Makkah, Saudi Arabia \\ mmnahas@uqu.edu.sa
}

\begin{abstract}
The microstrip patch antenna is used in various communication applications including cellular phones, satellites, missiles, and radars, due to its several attractive features such as small size and weight, low cost, and easy fabrication. The microstrip patch antenna consists of a top radiating patch, a bottom ground plane, and a dielectric substrate in between. The patch can have different shapes, the rectangular patch being the most commonly used. In practice, the microstrip antenna suffers from narrow bandwidth and low gain efficiency. This paper aims to enhance the bandwidth and efficiency of a rectangular-patch antenna using the High-Frequency Structure Simulator (HFSS). Initially different patch sizes and substrate materials are investigated and optimal antenna parameters are achieved. Then, the antenna performance is further enhanced by inserting single and double slot designs into the patch. Two cost-effective feeding methods are involved in the investigation. The antenna is designed to operate in the Super High Frequency (SHF) band.
\end{abstract}

Keywords-microstrip patch antenna; microwave; SHF; slot

\section{INTRODUCTION}

Among various antenna structures, the microstrip patch antenna is the most widely used nowadays because it can be easily installed (due to its low size, weight and cost) and fabricated on a printed circuit board $[1,2]$. The microstrip patch antenna is simply a metallic patch placed on a dielectric material and supported by a ground plane. There are different shapes that can be used for the patch, including rectangular, square, circular, triangular, semicircular, elliptical, diamond, hexagonal and bowtie [3]. However, the rectangular patch is the most common antenna geometry which has been extensively investigated [4]. Due to its simplicity and other advantages, the microstrip antenna is used for various applications including aircrafts, spacecrafts, satellites, missiles and mobile phones $[5,6]$. Typically, the antenna is fed by two methods: contacting and non-contacting. Contacting method is more attractive because it is easy to model and fabricate and simple to match the impedance. It uses either inset or probe feeding techniques. The inset feeding uses a microstrip line connected to the patch directly, while the probe feeding involves a coaxial cable connected to the ground and extended up to the patch. However, the main disadvantage of the contacting method is that it yields a low frequency bandwidth.
Non-contacting method involves the coupling of an electromagnetic field between the patch and the microstrip line. Although it results in better bandwidth, it is less attractive due to its high cost and difficulty of modeling and fabrication [7].

In effect, the microstrip patch antenna still suffers from narrow bandwidth and low gain efficiency especially in rectangular shape. The bandwidth is typically around $2-5 \%$ while the gain is $5-7 \mathrm{~dB}$ by single patch [8]. The reason is that electromagnetic fringing occurs from two sides of the patch only, thus the antenna radiates into half plane. Such fringing must be increased to enhance the antenna performance. There are several possible techniques to achieve this, for example, increasing the height (thickness) of the dielectric substrate. However, the thickness must not exceed $0.05 \lambda$, above which the antenna stops to radiate due to delivering the power into surface waves instead of transverse waves. Other options involve reducing of the dielectric constant or increasing the patch width from which the fringing takes place [8]. In fact, the patch width ultimately controls the radiation pattern as it is inversely proportional to the input impedance and directly proportional to the bandwidth. In contrast, the patch length has no significant contribution to the radiation and it is typically fixed at $\sim \lambda / 2$. However, its optimal value depends on the patch width and substrate parameters. Since the patch design, in general, plays important role in the antenna radiation, different patch shapes have been considered to enhance the antenna bandwidth and efficiency $[9,10]$, though introducing a slot into a simple patch shape is much more practical as it is very easy and can enhance the antenna fringing significantly [3]. Therefore, many studies have demonstrated slots in simple rectangular patch, but the maximum bandwidth achieved is still relatively low $(<5 \mathrm{GHz})[11-18]$.

This paper intends to further enhance the bandwidth and gain of the rectangular patch antenna. Various design options and their simulation results are demonstrated using the 1$30 \mathrm{GHz}$ frequency range to include the entire SHF band. A parametric study is initially performed to introduce a preliminary design, which involves different feeding methods, patch sizes and substrate materials. Then, the antenna performance is enhanced by cutting different slot designs into the patch using one and two slots. 


\section{PRELIMINARY DESIGN}

The preliminary design is based on a parametric study that commences by comparing the inset and coaxial feeding methods using the FR-4 epoxy substrate. Then, it goes through a sequence of empirical investigations including patch thickness, patch width, patch length, feedline width, substrate dimensions, and substrate material. As a result, the inset feeding yields higher bandwidth than coaxial feeding (see, for example, Figure 1 and Figure 5). The patch thickness has a negligible effect on the performance, thus $0.035 \mathrm{~mm}$ is decided to be used to ensure minimal antenna weight. However, the other parameters affect the radiation where the optimal empirical patch length and width are found to be $6 \mathrm{~mm}$ and $9 \mathrm{~mm}$ respectively. These values are in a very good agreement with the calculated ones using $10 \mathrm{GHz}$ operation frequency in the following equations $[17,18]$ :

$$
\begin{gathered}
\text { Width }(W)=\frac{c}{2 f_{o} \sqrt{\frac{\varepsilon_{r}+1}{2}}} \\
\operatorname{Length}(L)=\frac{c}{2 f_{o} \sqrt{\varepsilon_{e f f}}}-0.824 h\left(\frac{\left(\varepsilon_{e f f}+0.3\right)\left(\frac{W}{h}+0.264\right)}{\left(\varepsilon_{e f f}-0.258\right)\left(\frac{W}{h}+0.8\right)}\right)
\end{gathered}
$$

where $\varepsilon_{r}$ is the dielectric constant, $h$ is the substrate height, $f_{o}$ is the operation frequency and $\varepsilon_{\text {eff }}$ the effective permittivity that is given by:

$$
\varepsilon_{e f f}=\frac{\varepsilon_{r}+1}{2}+\frac{\varepsilon_{r}-1}{2}\left(\frac{1}{\sqrt{1+12\left(\frac{h}{W}\right)}}\right)
$$

The best inset feedline width is empirically $\sim 2.8 \mathrm{~mm}$ and the optimal substrate dimensions are $35 \times 35 \times 1.5 \mathrm{~mm}$. Finally, different common substrate materials are compared including Bakelite and RT duroid. The detailed results of the comparison are shown in Table I. Since frequency bandwidth is the most important parameter to consider in our research, RT duroid is decided to be used. However, the minimum reflection coefficient is reasonably low with such a dielectric.

TABLE I. DIELECTRIC MATERIAL RESULTS

\begin{tabular}{|c|c|c|c|c|c|}
\hline $\begin{array}{c}\text { Substrate } \\
\text { material }\end{array}$ & $\begin{array}{c}\boldsymbol{f}_{\boldsymbol{L}} \\
(\mathbf{G H z})\end{array}$ & $\begin{array}{c}\boldsymbol{f}_{\boldsymbol{H}} \\
(\mathbf{G H z})\end{array}$ & $\begin{array}{c}\text { Bandwidth } \\
(\mathbf{G H z})\end{array}$ & $\begin{array}{c}\text { Minimum } \\
\text { reflection } \\
\text { coefficient (dB) }\end{array}$ & $\begin{array}{c}\text { Minimum } \\
\text { reflection } \\
\text { frequency (GHz) }\end{array}$ \\
\hline $\begin{array}{c}\text { FR-4 } \\
\text { Epoxy }\end{array}$ & 3.7 & 10.1 & 6.4 & -32.4 & 6 \\
\hline Bakelite & 3.68 & 10.1 & 6.42 & -27 & 6.1 \\
\hline $\begin{array}{c}\text { RT } \\
\text { Duroid }\end{array}$ & 4.4 & 12 & 7.6 & -30.2 & 6.2 \\
\hline
\end{tabular}

Figure 1 shows the top-view design and results of our preliminary antenna using the optimal parameters obtained above. The results are depicted through the S11 curve that shows the power reflection coefficient vs frequency. Typically, the acceptable performance corresponds to $\leq-10 \mathrm{~dB}$ reflection. It is obvious that the antenna is ultra-wideband (UWB) where the frequency bandwidth reaches $7.6 \mathrm{GHz}$. According to the IEEE radio band designations, this antenna is suitable for the C-band (4 to $8 \mathrm{GHz}$ ) and $\mathrm{X}$-band (7 to $11.2 \mathrm{GHz})$ applications, which involve satellites, Wi-Fi, cordless telephones, surveillance, radar, and weather radar systems. It is most efficient for the next Wi-Fi generation [19] since the minimum reflection coefficient reaches $-30.2 \mathrm{~dB}$ at around $6 \mathrm{GHz}$ frequency.

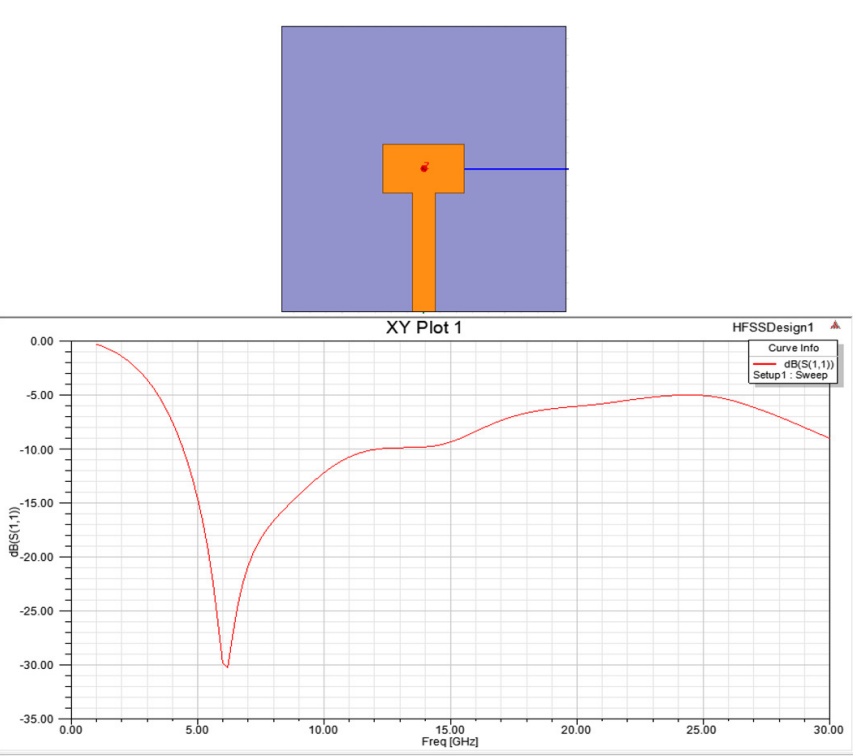

Fig. 1. Design and results of preliminary rectangular patch antenna

\section{ENHANCED DESIGNS AND RESULTS}

In this part, slot(s) is (are) added to the patch for further bandwidth and efficiency enhancement. Another parametric study is performed on each slot design, including size and position, such that the best design is empirically obtained. Single and double slots of the same shape are investigated respectively. Finally, the inset feedline is replaced by a coaxial cable for comparison. This is because coaxial feeding is the second easiest feeding method in fabrication after the inset method [7].

\section{A. Inset Feeding}

This section presents several slotted designs and their S11 results using inset feeding. Figure 2 shows the antenna design and results with a U-slot. The position of the slot center is $(-2.5,0) \mathrm{mm}$, given that $x$ is the vertical axis, $y$ is the horizontal axis, and negative $x$ is towards the top in our view. The slot width and length are 0.25 and $8 \mathrm{~mm}$ respectively, while each arm is $1.2 \mathrm{~mm}$ long. As a result, the bandwidth is increased up to $\sim 9.8 \mathrm{GHz}$ but the minimum reflection becomes $-27.7 \mathrm{~dB}$ at $6.4 \mathrm{GHz}$. This design is suitable for C-band, $\mathrm{X}$-band and some $\mathrm{Ku}$-band (12 to $18 \mathrm{GHz}$ ) applications where the higher frequency exceeds $14 \mathrm{GHz}$. Again, it is most efficient for the next Wi-Fi generation since the minimum reflection coefficient is still around $6 \mathrm{GHz}$.

Figure 3 shows the antenna design and results with a rectangular slot. The position of the slot center is $(-1,0) \mathrm{mm}$, while the slot length is $5.5 \mathrm{~mm}$ and its width is $0.25 \mathrm{~mm}$. Obviously, the bandwidth is enhanced to $11.5 \mathrm{GHz}$ where the higher frequency reaches $\sim 16.2 \mathrm{GHz}$. This antenna can operate in the C-band, X-band and most of the Ku-band which involves satellite broadcast services, space shuttle communication and 
International Space Station (ISS) communication. Moreover, the minimum reflection of this design is reduced down to $-41 \mathrm{~dB}$ at $7 \mathrm{GHz}$, which allows excellent operation in the next Wi-Fi generation band.

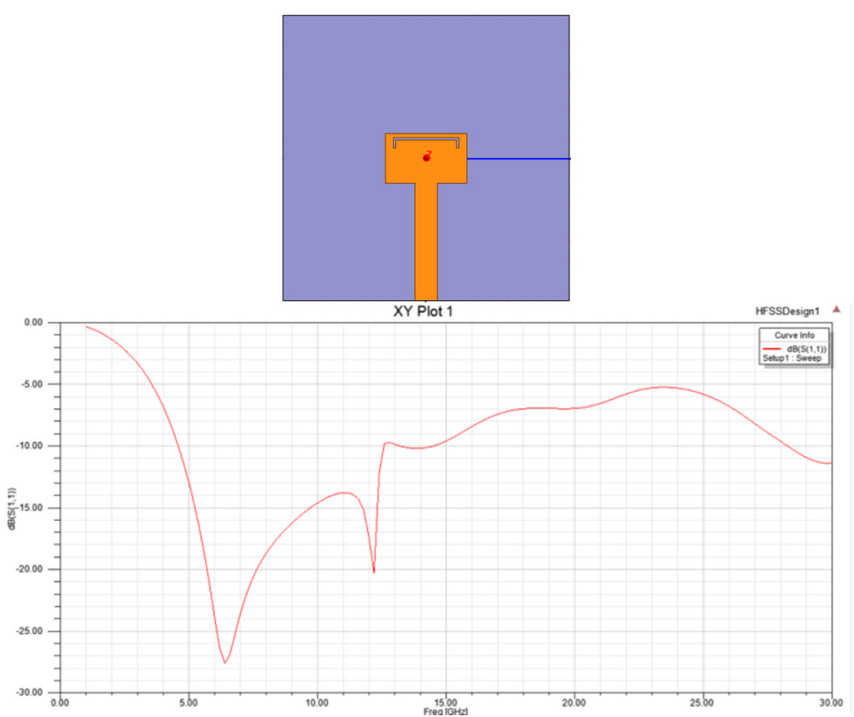

Fig. 2. Rectangular patch with U-slot. Design and results

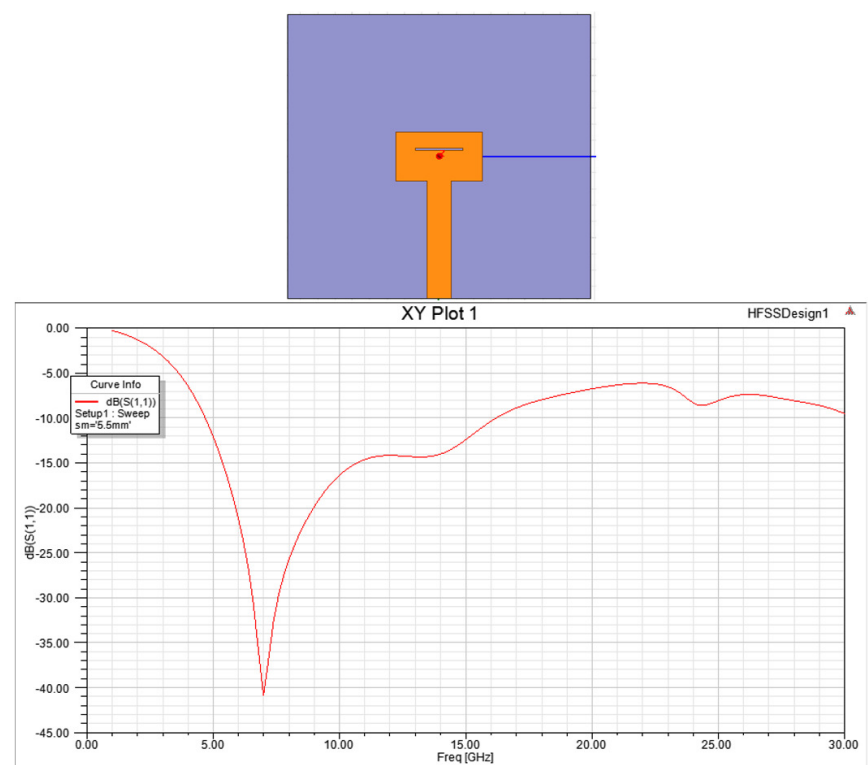

Fig. 3. Rectangular patch with rectangular slot. Design and results

Figure 4 shows the antenna design and results with double rectangular slots. The central position of slot 1 is $(-1,0) \mathrm{mm}$, the length is $5 \mathrm{~mm}$ and the width is $0.25 \mathrm{~mm}$. The position of slot 2 is $(-1.7,0) \mathrm{mm}$, the length is $9 \mathrm{~mm}$ and its width is $0.1 \mathrm{~mm}$. The resulting bandwidth is $10.2 \mathrm{GHz}$ since the higher frequency becomes less than $15 \mathrm{GHz}$. The minimum reflection coefficient is $-25.5 \mathrm{~dB}$ at $6.2 \mathrm{GHz}$. Again, this antenna has peak resonance at the next $\mathrm{Wi}-\mathrm{Fi}$ generation band, and it is generally suitable for applications of the $\mathrm{C}$-band, $\mathrm{X}$-band and $\mathrm{Ku}-\mathrm{b}$ and.

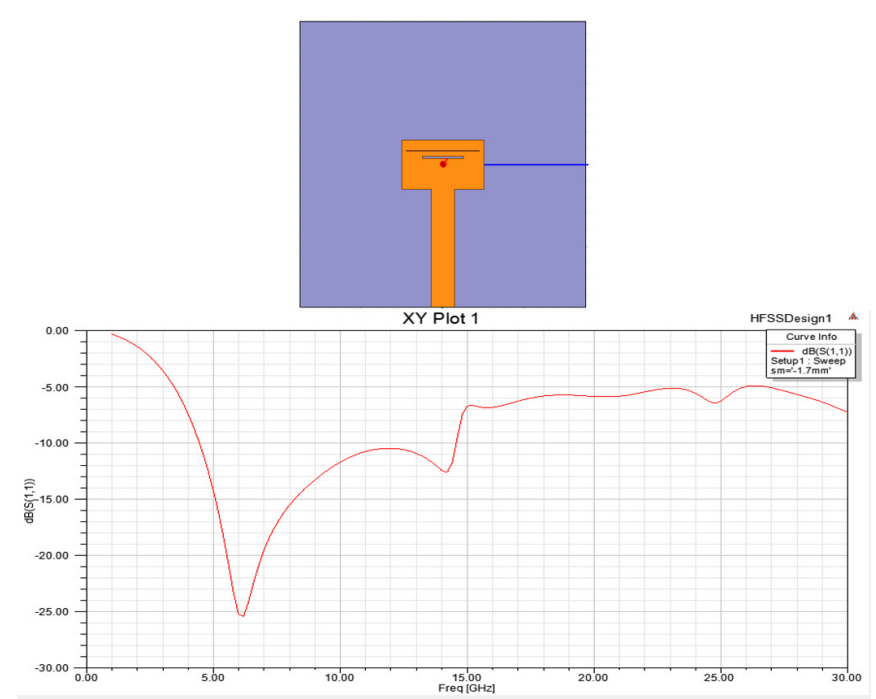

Fig. 4. Rectangular patch with double rectangular slots. Design and results

In addition, the same procedure is repeated for a rectangular patch with double U-slots. The first slot has the same dimensions and position of the one shown in Figure 2. The second slot is located around the origin and its width and length are $0.25 \mathrm{~mm}$ and $2.5 \mathrm{~mm}$ respectively. Again, the arm length is $1.2 \mathrm{~mm}$. As a result, the bandwidth is reduced to $7.1 \mathrm{GHz}$ and the minimum reflection becomes $-25 \mathrm{~dB}$ at $6 \mathrm{GHz}$. These values are worse than those of the preliminary design although they cover frequencies in the $\mathrm{X}-\mathrm{C}$ - - and $\mathrm{Ku}$-bands. This degradation can be understood as some fringing field components cancel each other, resulting in significant reduction of the overall radiation.

Table II summarizes the results achieved for the rectangular antenna using inset feeding. Obviously, the best design is corresponding to the single rectangular slot where the bandwidth reaches $11.5 \mathrm{GHz}$ and the minimum reflection coefficient drops down to $-41 \mathrm{~dB}$ at $7 \mathrm{GHz}$. However, other successful designs are achieved with double rectangular slots and single U-slot antenna, where the bandwidth is 10.2 and $9.8 \mathrm{GHz}$ respectively.

TABLE II. RECTANGULAR PATCH FED BY INSET FEEDLINE RESULTS

\begin{tabular}{|c|c|c|c|c|c|c|}
\hline Slot design & $\begin{array}{c}\boldsymbol{f}_{\boldsymbol{L}} \\
(\mathbf{G H z})\end{array}$ & $\begin{array}{c}\boldsymbol{f}_{\boldsymbol{H}} \\
(\mathbf{G H z})\end{array}$ & $\begin{array}{c}\text { Bandwidth } \\
(\mathbf{G H z})\end{array}$ & $\begin{array}{c}\text { Min. ref. } \\
\text { coef. (dB) }\end{array}$ & $\begin{array}{c}\text { Min. ref. } \\
\text { freq. (GHz) }\end{array}$ & $\begin{array}{c}\text { IEEE radio } \\
\text { bands }\end{array}$ \\
\hline Without slot & 4.4 & 12 & 7.6 & -30.2 & 6.2 & $\mathrm{C}, \mathrm{X}$ \\
\hline U-slot & 4.7 & 14.5 & 9.8 & -27.7 & 6.4 & $\mathrm{C}, \mathrm{X}, \mathrm{Ku}$ \\
\hline $\begin{array}{c}\text { Double } \\
\text { U-slots }\end{array}$ & 6.3 & 13.4 & 7.1 & -25 & 6 & $\mathrm{C}, \mathrm{X}, \mathrm{Ku}$ \\
\hline $\begin{array}{c}\text { Rectangular } \\
\text { slot }\end{array}$ & 4.7 & 16.2 & 11.5 & -41 & 7 & $\mathrm{C}, \mathrm{X}, \mathrm{Ku}$ \\
\hline $\begin{array}{c}\text { Double } \\
\text { rectangular } \\
\text { slots }\end{array}$ & 4.4 & 14.6 & 10.2 & -25.5 & 6.2 & $\mathrm{C}, \mathrm{X}, \mathrm{Ku}$ \\
\hline
\end{tabular}

\section{B. Coaxial Feeding}

In this part, the simulation results of using coaxial cable instead of inset feedline are shown. For comparison purposes, the antenna parameters and slots position and size are the same as before. 


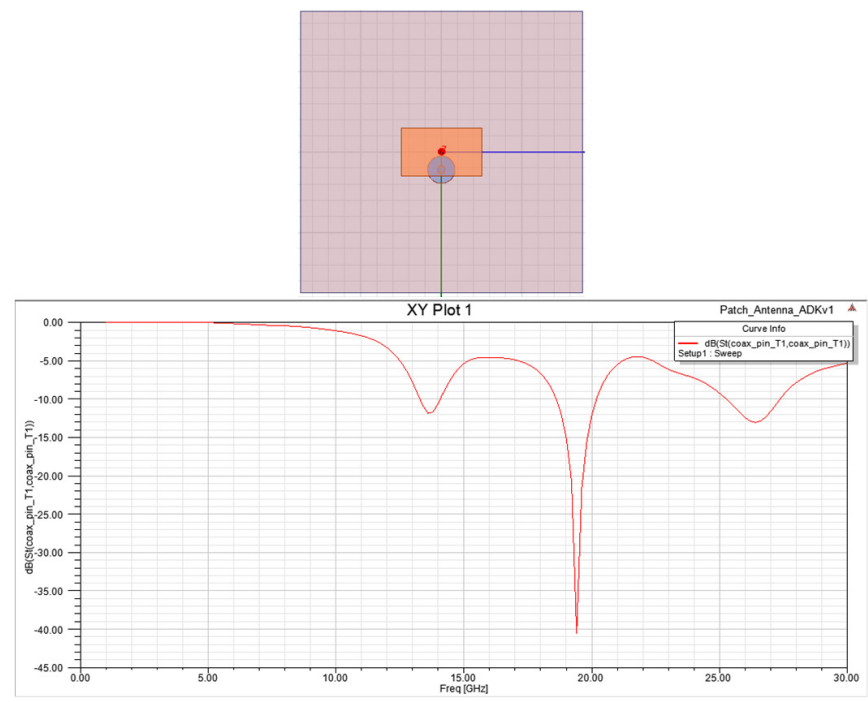

Fig. 5. Coaxially-fed rectangular patch without slot. Design and results

Figure 5 shows the design and results of the coaxially-fed antenna without slot. It is obvious that the antenna is no more UWB and becomes multiband, where peak resonance occurs discontinuously for a few specific frequencies at which reflection $\leq-10 \mathrm{~dB}$. The best resonance is at $19.3 \mathrm{GHz}$ where the reflection coefficient reaches $-40.3 \mathrm{~dB}$. However, other resonance peaks are observed around $13.7 \mathrm{GHz}$ and $25.2-27.3 \mathrm{GHz}$ with acceptable reflection coefficient values. This antenna is most efficient for applications operating around $19 \mathrm{GHz}$ which belongs in the K-band (18 to $27 \mathrm{GHz}$ ), which involves satellite, radar, and astronomical applications. The antenna can also operate at other frequencies in the same band including $25.2-27.3 \mathrm{GHz}$. It is also suitable for $\mathrm{Ku}$-band applications operating around $14 \mathrm{GHz}$.

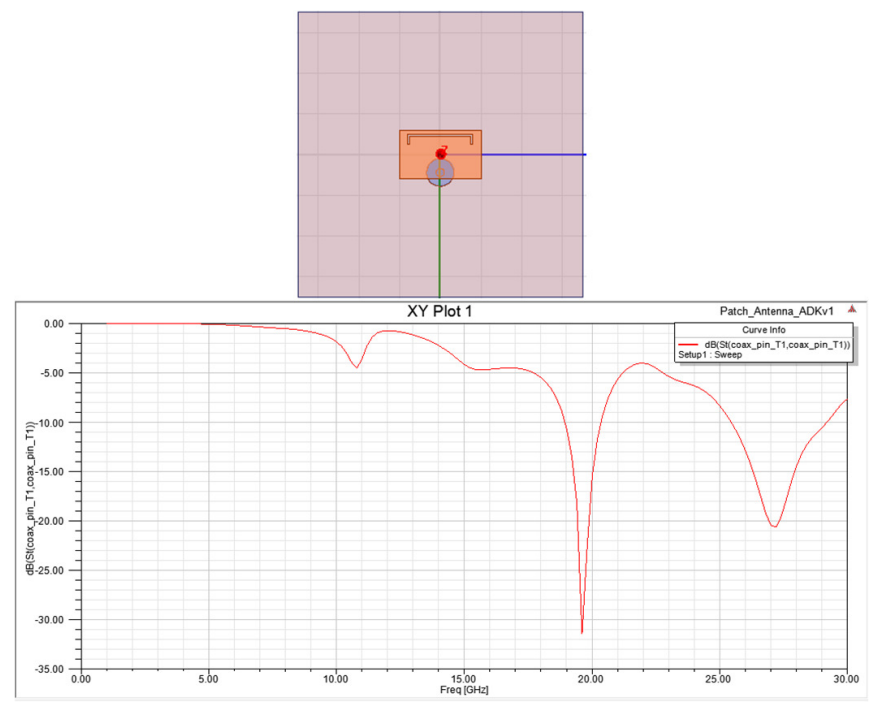

Fig. 6. Coaxially-fed rectangular patch with U-slot. Design and results

Figure 6 shows the design and results of the coaxially-fed antenna with U-slot. The best resonance is observed at $19.6 \mathrm{GHz}$ where the reflection is $-31.4 \mathrm{~dB}$. Moreover, the acceptable reflection is also seen between 25.5 and $29.1 \mathrm{GHz}$ where a reflection valley of $-20.6 \mathrm{~dB}$ is observed at $27.2 \mathrm{GHz}$. Again, this design is most efficient for applications operating around $19 \mathrm{GHz}$ in the $\mathrm{K}$-band. However, the resonance is expanded to include frequencies in the Ka-band (26.5 to $40 \mathrm{GHz}$ ), which is used for satellite communications and is also considered as the future spectrum for NASA communications.

Figure 7 shows the design and results of a coaxial patch antenna with a rectangular slot. The best reflection in the results reaches $-38 \mathrm{~dB}$ at $13 \mathrm{GHz}$. Other resonance peaks are obtained at 19.4 and $26.1 \mathrm{GHz}$ where the reflection is -26.8 and $-29.8 \mathrm{~dB}$ respectively. However, the antenna has continuous low reflection $(\leq-10 \mathrm{~dB})$ between 24.6 and $28 \mathrm{GHz}$. Obviously, the results are enhanced by this design as the antenna becomes efficient for applications operating around $13 \mathrm{GHz}$ in the $\mathrm{Ku}-$ band, $19 \mathrm{GHz}$ in the K-band and $26 \mathrm{GHz}$ in the Ka-band. It is also suitable for operation between 24.6 and $28 \mathrm{GHz}$.

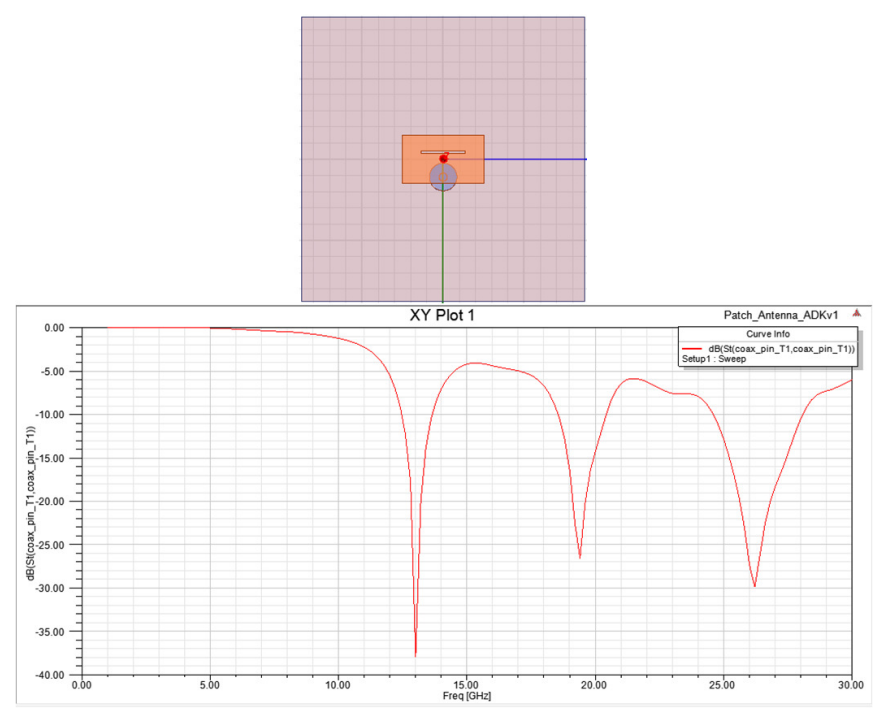

Fig. 7. Coaxially-fed rectangular patch with a rectangular slot. Design and results

Figure 8 shows the design and results of a coaxial patch antenna with double rectangular slots. As a result, resonance peaks are observed at 19.7 and $26.6 \mathrm{GHz}$ whose reflections are -26.3 and $-22.7 \mathrm{~dB}$ respectively. Moreover, the antenna has an acceptable reflection in the $24.5-28.9 \mathrm{GHz}$ range. This antenna is efficient for applications at 19.7 and $26.6 \mathrm{GHz}$ which are in the $\mathrm{K}$ - and Ka-band respectively. It is also suitable for any application between 24.5 and $29 \mathrm{GHz}$.

The same procedure is repeated for a coaxially-fed patch with double U-slots. Unfortunately, the reflection never drops below $-10 \mathrm{~dB}$, hence no resonance is observed. This is due to field opposition and cancellation that arises from the slots.

Table III summarizes the results achieved for our coaxiallyfed antenna. The best multiband design is corresponding to the single rectangular slot where three reflection valleys are obtained at $13,19.4$ and $26.1 \mathrm{GHz}$. An additional operating band is also seen between 24.6 and $28 \mathrm{GHz}$. 


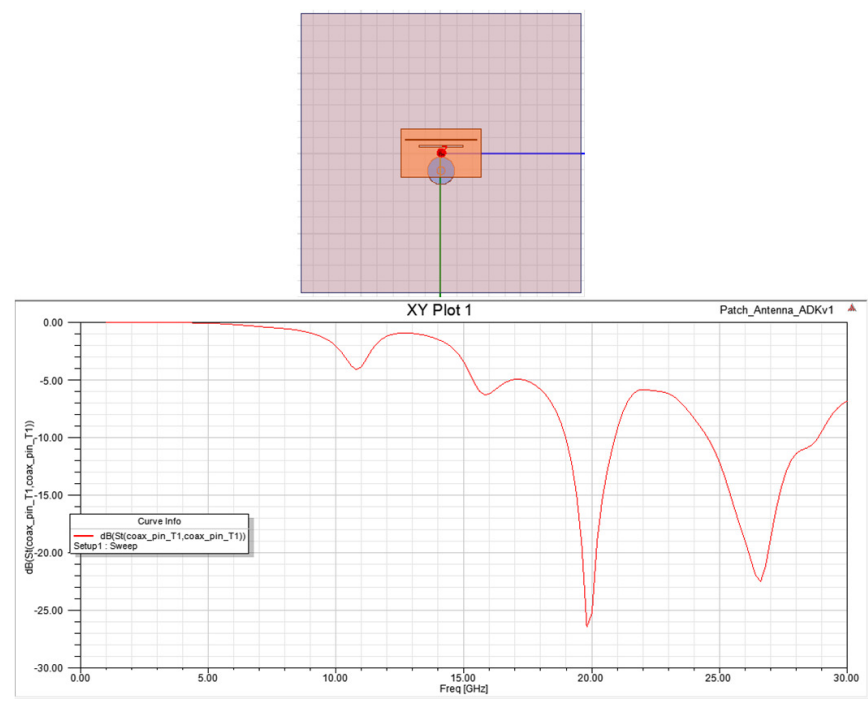

Fig. 8. Coaxially-fed rectangular patch with double rectangular slots. Design and results

TABLE III. RECTANGULAR PATCH FED BY COAXIAL CABLE RESULTS

\begin{tabular}{|c|c|c|c|c|c|c|}
\hline $\begin{array}{c}\text { Slot } \\
\text { design }\end{array}$ & $\begin{array}{c}\text { Min. } \\
\text { ref. } \\
\text { coef. } \\
\text { (dB) }\end{array}$ & $\begin{array}{c}\text { Min. } \\
\text { ref. } \\
\text { freq. } \\
\text { (GHz) }\end{array}$ & $\begin{array}{c}\text { 2nd res. } \\
\text { (GHz) }\end{array}$ & $\begin{array}{c}\text { 3rd res. } \\
\text { (GHz) }\end{array}$ & $\begin{array}{c}\text { Additional } \\
\text { resonance } \\
\text { (GHz) }\end{array}$ & $\begin{array}{c}\text { IEEE } \\
\text { radio } \\
\text { bands }\end{array}$ \\
\hline Without slot & -40.3 & 19.3 & - & - & $\begin{array}{c}13.7, \\
25.2-27.3\end{array}$ & $\mathrm{Ku}, \mathrm{K}$ \\
\hline $\begin{array}{c}\text { Double } \\
\text { U-slots }\end{array}$ & -31.4 & 19.6 & 27.2 & - & $25.5-29.1$ & $\mathrm{~K}, \mathrm{Ka}$ \\
\hline $\begin{array}{c}\text { Rectangular } \\
\text { slot }\end{array}$ & -38 & 13 & 19.4 & 26.1 & $24.6-28$ & $\mathrm{Ku}, \mathrm{K}$, \\
\hline $\begin{array}{c}\text { Double } \\
\text { rectangular } \\
\text { slots }\end{array}$ & -26.3 & 19.7 & 26.6 & - & $24.5-28.9$ & $\mathrm{Ka}, \mathrm{Ka}$ \\
\hline
\end{tabular}

\section{CONCLUSIONS}

This paper explored ways for enhancing the bandwidth and efficiency of a simple rectangular patch antenna using HFSS. At first, a preliminary design was introduced via optimizing the patch size and substrate material parameters. Further improvement was obtained by inserting different shapes of single and double slots into the patch. A comparison of two feeding methods was also carried out using inset and coaxial feeding. The results showed that the inset feeding is a better option as far as the frequency bandwidth is concerned. However, it was also proven that inserting slot(s) would improve the overall antenna performance significantly. In specific, a UWB antenna was successfully designed for SHF applications with $11.5 \mathrm{GHz}$ bandwidth using a single rectangular slot. Other UWB designs were also obtained with 10.2 and $9.8 \mathrm{GHz}$ bandwidth using double rectangular slots and single U-slot respectively. These designs are suitable for applications in the C-, X- and Ku-band. In addition, successful designs of multiband antenna using coaxial feeding along with a slotted patch were shown. Such antennas are efficient for operation at discrete frequencies, where the best design covers applications in the Ku-, K- and Ka-bands operating around 13, 19 and $26 \mathrm{GHz}$ respectively. They are also suitable for applications between 24.6 and $28 \mathrm{GHz}$. However, the UWB results achieved by inset feeding are the most attractive ones in this research.

\section{ACKNOWLEDGMENT}

The authors would like to thank Ali Al-Yahyaoui and Madi Al-Hazmi for their valuable assistance during this research.

\section{REFERENCES}

[1] N. Singh, S. Kumar, B. K. Kanaujia, "A new trend to power up nextgeneration Internet of Things (IoT) devices:'rectenna",, in: Energy Conservation for IoT Devices, pp. 331-356, Springer, 2019

[2] A. Joret, M. F. L. Abdullah, M. S. Sulong, "Simulation of GPR system design using CST microwave and Matlab", Yanbu Journal of Engineering and Science, Vol. 14, pp. 49-57, 2017

[3] V. P. Patil, "Enhancement of bandwidth of rectangular patch antenna using two square slots techniques", International Journal of Engineering Sciences \& Emerging Technologies, Vol. 3, No. 2, pp. 1-12, 2012

[4] S. Chattopadhyay, M. Biswas, J. Y. Siddiqui, D. Guha, "CAD of mechanically tunable rectangular microstrip patch with variable aspect ratio", IEEE Applied Electromagnetics Conference, Kolkata, India, December 19-20, 2007

[5] S. R. Emadian, J. Ahmadi-Shokouh, "Very small dual band-notched rectangular slot antenna with enhanced impedance bandwidth", IEEE Transactions on Antennas and Propagation, Vol. 63, No. 10, pp. 4529 4534, 2015

[6] M. U. Khan, M. S. Sharawi, R. Mittra, "Microstrip patch antenna miniaturisation techniques: a review", IET Microwaves, Antennas \& Propagation, Vol. 9, No. 9, pp. 913-922, 2015

[7] A. Kumar, J. Kaur, R. Singh, "Performance analysis of different feeding techniques", International Journal of Emerging Technology and Advanced Engineering, Vol. 3, No. 3, pp. 884-890, 2013

[8] A. Chaudhary, D. C. Dhukaiya, "Analysis and bandwidth enhancement by cutting pi and rectangular slot in rectangular mictrostrip antenna for broadband applications", International Journal of Enhanced Research in Science Technology \& Engineering, Vol. 3, No. 1, pp. 431-437, 2014

[9] K. N. Lal, A. K. Singh, "Modified design of microstrip patch antenna for WiMAX communication system", 2014 IEEE Students' Technology Symposium, Kharagpur, India, February 28-March 2, 2014

[10] S. Mahmoud, W. Swelam, M. Hassan, "Parametric study of slotted ground microstrip patch antenna", IOSR Journal of Electronics and Communication Engineering, Vol. 11, No. 1, pp. 1-8, 2016

[11] H. F. Abu Tarboush, H. S. Al-Raweshidy, R. Nilavalan, "Bandwidth enhancement for microstrip patch antenna using stacked patch and slot", 2009 IEEE International Workshop on Antenna Technology, Santa Monica, USA, March 2-4, 2009

[12] R. J. Chitra, V. Nagarajan, "Double L-slot microstrip patch antenna array for WiMAX and WLAN applications", Computers \& Electrical Engineering, Vol. 39, No. 3, pp. 1026-1041, 2013

[13] L. Agarwal, S. Gandhi, S. Malik, S. Vijay, T. S. Chauhan, "Design and analysis of rectangular patch with square slots", International Journal of Scientific Research and Management Studies, Vol. 3, No. 1, pp. 15-20

[14] K. F. Tong, K. M. Luk, K. F. Lee, R. Q. Lee, “A broad-band U-slot rectangular patch antenna on a microwave substrate", IEEE Transactions on Antennas and Propagation, Vol. 48, No. 6, pp. 954-960, 2000

[15] S. Chatterjee, "Compact microstrip patch antenna for microwave communication”, Indian Journal of Pure \& Applied Physics, Vol. 51, No. 11 , pp. $800-807,2016$ 
[16] G. Chaouki, N. Omrane, G. Said, G. Ali, “An electrical model to U-Slot patch antenna with circular polarization", International Journal of Advanced Computer Science and Applications, Vol. 8, No. 3, pp. 62-66, 2017

[17] A. Rani, R. K. Dawre, "Design and analysis of rectangular and U slotted patch for satellite communication", International Journal of Computer Applications, Vol. 12, No. 7, pp. 36-40, 2010

[18] A. Burcakbas, S. Soylu, B. Bektas, S. T. Imeci, "Square shape patch antenna with triangular slot", 2017 International Applied Computational Electromagnetics Society Symposium, Firenze, Italy, March 26-30, 2017

[19] M. S. Afaqui, E. Garcia-Villegas, E. Lopez-Aguilera, "IEEE 802.11ax: challenges and requirements for future high efficiency WiFi", IEEE Wireless Communications, Vol. 24, No. 3, pp. 130-137, 2017 